\title{
Adaptation of the sensor method for the determination of mixing time in a rocking single-use bioreactor
}

\author{
Mateusz Bartczak, Kamil Wierzchowski, Maciej Pilarek \\ Faculty of Chemical and Process Engineering, Warsaw University of Technology, POLAND, Warsaw, \\ Waryńskiego 1, E-mail: mateusz.bartczak.dokt@pw.edu.pl (MB), kamil.wierzchowski.dokt@pw.edu.pl (KW), \\ maciej.pilarek@pw.edu.pl (MP)
}

\begin{abstract}
The aim of the study was to determine the characteristics of mixing time in a rocking singleuse bioreactor equipped with a 2-litre bag-like container by the sensor method. Results have shown that the frequency of rocking movement has the biggest influence on the values of mixing time.
\end{abstract}

Keywords - single-use bioreactor, wave-type agitation, rocking motion, mixing time, sensor method, design of experiments.

\section{Introduction}

Nowadays, single-use bioreactors (SUBs) have gained significant applicability across the whole bioprocess and biopharmaceutical industries. The distinctive feature of SUBs is the use of disposable bag-like containers, as vessels made from multi-layer plastics [1]. Many different SUBs are currently available on the market, with rocking bioreactors being the most popular [2]. The liquid phase inside a bag-like container is agitated by the oscillatory movement of the bioreactor platform - this motion results in wave propagation on the liquid surface. Rocking bioreactors are appreciated for their very gentle mixing mechanism, suitable for fragile biomass, e.g. shear-sensitive mammalian cells cultures and integrated forms of biomass, e.g. hairy roots, and bubble-free aeration without sparging equipment $[2,3]$.

Hydrodynamical properties of liquid flow inside rocking SUBs are not fully systematised. Hence, the aim of this study was to quantitatively determine the influence of operating parameters defining wave-assisted agitation on the values of mixing time reached in commercially available WAVE 25 bioreactor. Mixing time is a parameter that allows for easy assessment of mixing quality inside the system and is recognised as an important feature that affects the applicability of bioreactors in bioprocess engineering [4].

\section{Materials and methods}

ReadyToProcess WAVE 25 (GE Healthcare) bioreactor system was utilised. The bioreactor was equipped with Cellbag $2 \mathrm{~L}$ disposable bag-like container (Fig. 1).

The mixing time values were determined using the sensor method. A conventional $\mathrm{pH}$ electrode was used (EPP-1, Elmetron, Poland) to monitor $\mathrm{pH}$ values after injection of a tracer. Data acquisition was performed automatically via a universal meter (CX-401, Elmetron, Poland). The electrode was mounted on the upper side of the vessel (Fig. 2).

Mixing time was defined as the moment in which the value of homogeneity $\mathrm{Ho}$ entered the range of $100 \% \pm 5 \%$ for the last time (based on [4]). Ho was calculated from the following equation:

$$
H o(t)=\frac{p H(t)-p H_{0}}{p H_{\infty}-p H_{0}}
$$

In each experiment, $2.5 \mathrm{~mL} / \mathrm{L}$ of the tracer $(\mathrm{NaOH}$ solution, $0.5 \mathrm{~mol} / \mathrm{L})$ was added to an $\mathrm{HCl}$ solution of $\mathrm{pH}=3$. The measurement of $\mathrm{pH}$ changes was started at the timepoint of tracer injection. 


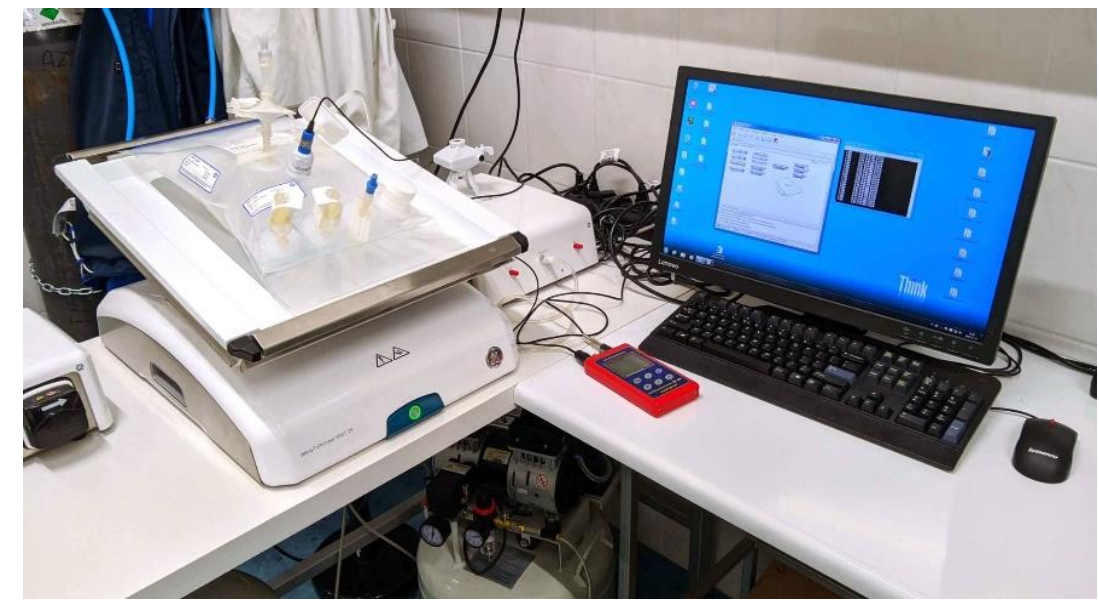

Fig. 1. Experimental setup: ReadyToProcess WAVE 25

bioreactor and the CX-401 meter connected to a computer.

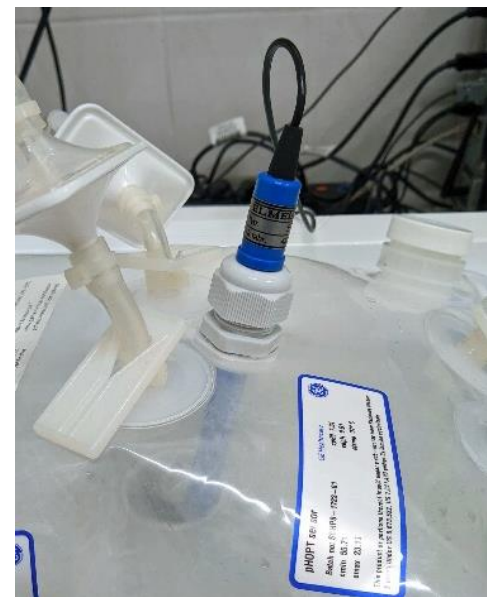

Fig. 2. pH electrode mounted on the Cellbag $2 \mathrm{~L}$ vessel.

Four bioreactor operating parameters were investigated with regards to their significant or insignificant influence on the values of mixing time: rocking angle, rocking frequency, volume of liquid inside the vessel and rocking acceleration. A design of experiments (DoE) approach was used to plan the experimental values of the parameters. With three selected values for each parameter, a full experimental plan consisted of 81 variants. In total, 243 measurements have been performed.

\section{Results}

Average values of mixing time for the experimental values of operating parameters are presented in Table 1.

Table 1. Average values of mixing time based on the experimental data.

\begin{tabular}{llr}
\hline $\begin{array}{l}\text { Operating } \\
\text { parameter }\end{array}$ & $\begin{array}{l}\text { Experimental } \\
\text { value }\end{array}$ & \multicolumn{2}{l}{$\begin{array}{l}\text { Average } \\
\text { mixing time } \\
(\mathrm{s})\end{array}$} \\
\hline Rocking & 2 & 451 \\
frequency & 21 & 36 \\
$\left(\mathrm{~min}^{-1}\right)$ & 40 & 5 \\
\hline Rocking & 2 & 269 \\
angle $\left(^{\circ}\right)$ & 7 & 150 \\
& 12 & 73 \\
\hline
\end{tabular}

$\begin{array}{lll}\text { Operating } & \text { Experimental } & \text { Average } \\ \text { parameter } & \text { value } & \text { mixing time }\end{array}$

(s)

\begin{tabular}{lrr}
\hline Volume of & 0.2 & 72 \\
liquid & 0.6 & 186 \\
$\left(\mathrm{dm}^{3}\right)$ & 1.0 & 235 \\
\hline Accelera- & 30 & 160 \\
tion $(\%)$ & 60 & 166 \\
& 90 & 167 \\
\hline
\end{tabular}

\section{Conclusions}

In the studied system, the measured values of mixing time ranged from 3 to $1800 \mathrm{~s}$. According to the acquired data, parameters that significantly influenced the mixing times in a rocking bioreactor are the rocking angle, rocking frequency, and liquid volume. The parameter which has the most substantial impact on the mixing time was the rocking frequency. The rocking acceleration parameter showed no significant influence on experimentally reached values of mixing time.

Performed adaptation of the sensor method proved to be an effective way of measuring mixing time in the studied system. The adaptation allows for the potential use of different sensors and could be applied in similar setups. 


\section{Acknowledgments}

Research was funded by the Warsaw University of Technology, grant IChem-1.

\section{References}

[1] Vanhamel, S., \& Piton, C. (2019). Production of Disposable Bags - A Manufacturer's Report. In Single-Use Technology in Biopharmaceutical Manufacture (pp. 95-116). John Wiley \& Sons, Ltd. https://doi.org/10.1002/9781119477891.ch8

[2] Jossen, V., Eibl, R., \& Eibl, D. (2019). Single-Use Bioreactors - An Overview. In SingleUse Technology in Biopharmaceutical Manufacture (pp. 37-52). John Wiley \& Sons, Ltd. https://doi.org/10.1002/9781119477891.ch4

[3] Pilarek, M., Sobieszuk, P., Wierzchowski, K., \& Dąbkowska, K. (2018). Impact of operating parameters on values of a volumetric mass transfer coefficient in a single-use bioreactor with wave-induced agitation. Chemical Engineering Research and Design, 136, 1-10. https://doi.org/10.1016/j.cherd.2018.04.012

[4] Bauer, I., Dreher, T., Eibl, D., Glöckler, R., Husemann, U., John, G. T., Kaiser, S. C., Kampeis, P., Kauling, J., Kleebank, S., Kraume, M., Kuhlmann, W., Löffelholz, C., Meusel, W., Möller, J., Pörtner, R., Sieblist, C., Tscheschke, B., \& Werner, S. (2020). Recommendations for process engineering characterisation of single-use bioreactors and mixing systems by using experimental methods (2nd Edition). Dechema Biotechnologie. https://dechema.de/en/Single_Use_PE_Characterization-path-123211,124930.html 